ISSN on-line: 1982-9949

Doi: $10.17058 /$ rea.v25i2.8946

\title{
EDUCAÇÃO POPULAR E DOCÊNCIA ${ }^{1}$
}

\author{
Antonio Ademar Guimarães ${ }^{2}$ \\ Paloma de Freitas Daudt ${ }^{3}$ \\ Luise Toleto Kern ${ }^{4}$
}

A obra Educação Popular e Docência está inserida na coleção Docência em Formação, integrando a série Educação de Jovens e Adultos. Pensar a educação popular na contemporaneidade significa reafirmar o sentido e o compromisso de uma educação para e com o povo latino-americano. Dessa forma, os autores da obra compreendem a educação popular como uma prática educativa e uma proposta pedagógica que está atravessada pela história latino-americana. Por ocupar este espaço, "se alimenta das lutas de resistência e da criatividade dos povos da América Latina e, por isso, valoriza os conhecimentos aqui produzidos" (STRECK et al. 2014, p. 22).

O livro inicia apresentando, como convite para aprofundamento, fontes teóricas entendidas como importantes para a construção da educação popular e que traçam características para a identidade desta prática. A discussão continua no questionamento sobre quem é o educador popular, permitindo pensar onde este sujeito está inserido e que comprometimento se revela diante do contexto social e da vida. Na sequência, problematizase de que maneira a educação popular está presente no espaço das políticas públicas e a relação desta prática educativa com a pesquisa, possibilitando reflexões e ferramentas que permitam o educador e a educadora a perceber a dimensão da pesquisa como parte da docência (STRECK et al. 2014, p. 24). É importante destacar que a contextualização histórica atravessa toda a obra. Os autores também se dedicam a pensar como se forma e quem forma o educador e a educadora e, por fim, qual a relação entre a educação popular e a educação de jovens e adultos.

Para tanto a obra é organizada em sete capítulos que perpassam pelos seguintes temas: Educação com o povo: Notas históricas; Aproximações teóricas em Educação Popular; Quem é o educador popular?; Educação Popular e políticas públicas: entre o instituído e o

\footnotetext{
${ }^{1}$ STRECK, D. R. et al. Educação Popular e Docência. 1. ed. São Paulo: Cortez, 2014.

${ }^{2}$ Doutorando em Educação no Programa de Pós-Graduação em Educação - Unisinos. Endereço: Av. Unisinos, 950 - Cristo Rei, São Leopoldo - RS, 93022-000, Prédio B09.

${ }^{3}$ Mestranda em Educação no Programa de Pós-Graduação em Educação - Unisinos. Bolsista Capes/PROEX. Endereço: Av. Unisinos, 950 - Cristo Rei, São Leopoldo - RS, 93022-000, Prédio B09.

${ }^{4}$ Bolsista de Iniciação Científica no Programa de Pós-Graduação em Educação - Unisinos. Probic/Fapergs. Endereço: Av. Unisinos, 950 - Cristo Rei, São Leopoldo - RS, 93022-000, Prédio B09.
}

Revista Reflexão e Ação, Santa Cruz do Sul, v. 25, n. 2, p. 289-294, Maio./Ago. 2017. http://online.unisc.br/seer/index.php/reflex/index 
instituinte; Pesquisa-educação: Prática docente e investigativa; A formação do educador popular; Educação Popular e educação de jovens e adultos em diálogo.

Esta resenha foi desenvolvida a partir de uma leitura crítica do livro, cujo conjunto foi explorado em sete partes de acordo com os capítulos, para fins de análise. Com este procedimento procuramos, por um lado, partilhar de maneira uniforme entre os autores, a responsabilidade e o esforço exigidos pela leitura. E de outro, possibilitar uma análise o mais qualificada possível, oferecendo aos leitores e às leitoras uma noção abrangente e fiel ao seu conteúdo.

O primeiro capítulo "Educação com o povo: notas históricas" reflete sobre a memória da educação popular, criticando as práticas educativas hegemônicas que contribuem para a invisibilidade de autoras e autores que "combinam educação com um projeto de sociedade" (STRECK et al. 2014, p. 29). Esta seção aborda a educação popular a partir de dois aspectos que marcam sua história: a concepção do popular na educação e algumas "caracterizações históricas de uma educação feita com e para o povo e em seu favor” (STRECK et al. 2014, p. 29). Para tal, o capítulo é organizado em cinco subcapítulos: Sobre o "popular": sentidos e significados; Educação Popular na América Latina: entre projetos educativos e o (re)fundacional; Sobre algumas experiências libertadoras na América Latina; A educação Popular no Brasil; Considerações finais.

As diversas formas de entender o popular podem dar significados diferentes à prática educativa. Neste sentido, inspirados por Brandão, toma-se a uma posição que não "desvincula da educação popular seu sentido político e de classe, o que pressupõe: processo de libertação via conscientização e luta política" (STRECK et al. 2014, p. 32). Esta concepção está vinculada à história da educação popular que se relaciona diretamente com a trajetória de luta dos movimentos sociais populares.

Assim, é possível compreender que a construção da educação popular se baseia nos ensinamentos dos povos indígenas, população do campo e da cidade, trabalhadores(as), operários(as), artesãs(ãos), população negra, população LGBTTTs, pescadores(as), jovens, mulheres, assentados(as), assim como acampados(as) e tantas outras comunidades que historicamente foram marginalizadas e que através das lutas diárias procuram se tornar protagonistas das suas histórias. Este capítulo encontra-se mergulhado na memória e saber a nossa história nos faz viver. Portanto, se faz importante de conhecer a história da educação para caminhar para a transformação e assim, "defender a desmercantilização da educação" (STRECK et al. 2014, p.49). 
$\mathrm{Na}$ continuidade dos capítulos atinge-se uma compreensão maior sobre as perspectivas teóricas que se articulam com o processo de construção do que se entende por educação popular. Então, seguindo este objetivo, o segundo capítulo "Aproximações teóricas em educação popular" está organizado em três partes: Aproximações teóricas clássicas; Aproximações teóricas interdisciplinares; Desafios teóricos atuais.

Nesta discussão, os autores refletem sobre a educação popular como um processo dialético e dialógico, passam a considerar a cultura como sua base fundante no continente latino-americano (STRECK et al. 2014, p. 54). Durante a leitura fica exposta a grande importância do pensamento de Paulo Freire, assim como as correntes, autores e autoras que o influenciaram. Dessa forma, percebe-se que as aproximações teóricas da educação popular se formam na diversidade. É possível encontrar correntes do pensamento clássico ocidental, além de teorias fundadas na realidade latino-americana, porém é importante destacar que se trata de influências de autores e autoras que denunciam a dominação e acreditam na resistência e no protagonismo do povo oprimido.

Já o capítulo III, intitulado $O$ que é Educação Popular?, inicia um resgate histórico da educação popular na América Latina, destacando a importância das contribuições de José Martí como um percursor de Paulo Freire. Martí era um defensor da educação para com o povo e como um dos principais fundamentos para libertação de Cuba. Assim como para Paulo Freire, a educação é o principal fundamento para a emancipação dos sujeitos. Uma importante definição apresentada pelos autores é de que “[...] a educação popular é constituída de uma educação comprometida e participativa orientada pela perspectiva de realização de todos os direitos do povo" (STRECK et al. 2014, p. 82). Esta seção ainda está dividida em cinco partes: Explorando a expressão educador popular; Autonomia e rebeldia na ação de ser educador popular; Criatividade metodológica; Respeito às culturas locais; Leitura da realidade.

$\mathrm{Na}$ quarta seção, na qual são abordadas questões referentes à educação popular e políticas públicas, os autores evidenciam algumas relações entra a educação popular e o Estado, perpassando pelas políticas de assistência social e organizações da sociedade civil (ONGs), as democratizações do processo de decisões sobre o orçamento público e alguns dilemas da construção do marco de referência da educação popular para políticas públicas.

Em um quinto momento a obra trata da prática docente e investigativa, trazendo o pensando de Freire quanto à ideia de que a tarefa educativa sempre é uma tarefa investigativa, ou seja, “[...] ensinar/aprender e investigar/pesquisar são dimensões ou práticas do mesmo processo de conhecer" (STRECK et al. 2014, p. 131). O capítulo está desenvolvido sob dois Revista Reflexão e Ação, Santa Cruz do Sul, v. 25, n. 2, p. 269-294 Maio./Ago. 2017.

http://online.unisc.br/seer/index.php/reflex/index 
eixos: As vertentes em pesquisa-educação e Princípios - apresenta o encontro de perspectivas teórico-metodológicas que compõem o campo da pesquisa-ação, pesquisa participante, ou pesquisa-ação participante, ou sistematização de experiências - e convergências metodológicas da pesquisa-educação - identifica alguns princípios ou convergências metodológicas comum com essas diversas práticas com objetivo de possibilitar o diálogo com a prática educativa.

No capítulo VI sobre a formação do educador popular, os autores propõem algumas reflexões ancoradas no princípio da incompletude, desenvolvendo os " [...] saberes acadêmicos e saberes da experiência do ser educador e educadora popular, na relação com os demais seres da sua convivência" (STRECK et al. 2014, p. 157). Já para Paulo Freire na Pedagogia dos Sonhos Possíveis (2001), orienta o quanto é importante destacar que o educador precisa conhecer a história dos seus pais, da sua cultura e do seu país, pois para ele a "Formação é uma experiência permanente, que não para nunca" (FREIRE, 2001, p. 245). Depois de conhecer a sua história, o educador poderá através da sua convivência enriquecer as suas possibilidades de geração de novas experiências.

O capítulo está organizado em 8 partes, com uma introdução, seis eixos, mais as considerações finais do capítulo. No primeiro eixo os autores questionam quem forma e onde se forma o educador popular?, e partem da ideia de que a formação ultrapassa as fronteiras físicas, e que o respeito a pluralidade das agências formadoras e dos agentes formadores é um dos pontos que merece destaque e são legitimados na relação entre os educandos e educandas.

O eixo dois aponta para a necessidade de que os educadores e as educadoras consigam: compreender-se no binômio educador-educando. Indica o amor e o respeito como pontos centrais para convivência entre o educador e o educando. As (Des)construções coletivas, é o título do eixo três que, para os autores, só se concretiza a partir dos processos de participação, geridos pela ação do educador e da educadora popular nas suas práticas educacionais. Para os autores: "Um educador, ciente de que um processo de formação implica em estar aberto para alterar conceitos, por vezes nunca questionados, sugere que precisamos estar pré-dispostos à mudança para alterar aquilo que a gente tem como algo certo" (FREIRE, 2001, p. 164).

$\mathrm{O}$ eixo quatro destaca que as Práticas educativas a serviço da autoridade e da liberdade precisam estar apoiadas no legado de Paulo Freire, pautado pela amorosidade, diálogo, companheirismo, generosidade, compromisso, ética, estética e que cujas relações de autoridade dos educadores e educadoras podem ser desenvolvidas na horizontalidade e não em concepções verticalistas. Neste eixo, a obra apresenta alguns relatos de prática de educadores(as) entrevistados(as) pelos autores.

Revista Reflexão e Ação, Santa Cruz do Sul, v. 25, n. 2, p. 269-294 Maio./Ago. 2017.

http://online.unisc.br/seer/index.php/reflex/index 
O quinto eixo aponta para a dimensão dos conflitos, que são definidos como "próprios das sociedades humanas" (STRECK et al. 2014, p.168). E para o melhor desenvolvimento das atividades dos educadores e educadoras, faz-se necessário apostarmos nos educandos e educandas, com uma postura que valoriza o que temos em comum com os demais; evitando destacar o que os educandos e as educandas sabem ou não, evitando fazer comparativos entre ambos.

$\mathrm{O}$ eixo seis trata sobre os Saberes instituintes e instituídos na prática do educador popular, sendo que o saber fazer é uma premissa que merece destaque nos caminhos da educação popular. Nas considerações finais do capítulo, é destacado que: “[...] por se fazer na cultura de sujeitos históricos, a educação requer aprendizagens que devem ser ensinadas, aprendidas e desenvolvidas todos os dias. Esta é uma tarefa de toda a vida e da vida de todos" (STRECK et al. 2014, p. 175).

O sétimo e último capítulo sob o título de Educação popular e educação de jovens $e$ adultos em diálogo, teve a sua construção concretizada através da cooperação entre os autores e colaboradores. Foi estruturado em forma de diálogo, com a intenção de apoiar a convergência das reflexões. Nesta estrutura de diálogo, os seis autores realizaram entre si oito questões, que buscam apresentar aos leitores relatos de práticas que podem apoiar com estratégias e ferramentas de apoio nas ações de EJA e outros espaços da educação popular.

Para os autores, parte dos nossos problemas com a educação situa-se no fato de sempre estarmos buscando soluções "mágicas" e que em um curto espaço de tempo são abandonadas. Uma das possibilidades de minimizarmos estes equívocos nas nossas ações educacionais está apoiada nos ideais de Freire, que afirma que sempre que tivermos dúvida se as nossas ações pedagógicas estão certas ou não, então estaremos certos sempre que estivermos pensando em ações práticas que seriam desenvolvidas com os nossos alunos e alunas. As teorias, metodologias e exemplos práticos são apresentados aos leitores na realização dos questionamentos e na apresentação das respostas completas. Na parte final do capítulo é reconhecida a existência de limites e condicionantes, que acabam dificultando o desenvolvimento das práticas pedagógicas, que buscam valorizar as ações práticas, assinalando-se, entretanto, que estas contradições não podem nos paralisar. Por fim, o livro destaca nas duas últimas páginas, 10 sites que oferecem material de apoio e que podem ser consultados nos estudos e práticas sobre EJA e a própria Educação Popular.

O livro tem o mérito de reunir sete capítulos de qualidade sobre o tema da educação popular, cuja abordagem clara e acessível ao leitor, permite sugerir sua adoção por professores em processo de formação e interessados na temática. Oferece subsídios tanto para Revista Reflexão e Ação, Santa Cruz do Sul, v. 25, n. 2, p. 269-294 Maio./Ago. 2017.

http://online.unisc.br/seer/index.php/reflex/index 
estudantes universitários como para docentes, a fim de que possam planejar e desenvolver suas atividades com base na educação popular, principalmente no campo da docência.

\section{Referências}

FREIRE, Paulo. Pedagogia dos sonhos possíveis. 2 ed. São Paulo: UNESP, 2001.

STRECK, D. R. et al. Educação popular e docência. 1. ed. São Paulo: Cortez, 2014. 